\title{
Fracture Energy Measurement of Prismatic Plane and $\Sigma 2$ Boundary in Cemented Carbide
}

\author{
MAX EMMANUEL, ${ }^{1,4}$ ORIOL GAVALDA-DIAZ, ${ }^{1}$ GIORGIO SERNICOLA, ${ }^{1}$ \\ RACHID M'SAOUBI, ${ }^{2}$ TOMAS PERSSON,${ }^{2}$ SUSANNE NORGREN,${ }^{3}$ \\ KATHARINA MARQUARDT,${ }^{1}$ T. BEN BRITTON,${ }^{1}$ and FINN GIULIANI ${ }^{1}$ \\ 1.-Department of Materials, Imperial College London, London SW7 2AZ, UK. 2.-R\&D Material \\ and Technology Development, Seco Tools AB, 73782 Fagersta, Sweden. 3.-Stockholm \& Division \\ of Production and Materials Engineering, Lund Technical University, Sandvik R\&D, Lerkrogsv. \\ 13, 12680 Lund, Sweden. 4.—e-mail: max.emmanuel13@imperial.ac.uk
}

The grain boundary network of WC in WC-Co is important, as cracks often travel intergranularly. This motivates the present work, where we experimentally measure the fracture energy of $\Sigma 2$ twist grain boundaries between WC crystals using a double cantilever beam opened with a wedge under displacement control in a WC-10wt\%Co sample. The fracture energy of this boundary type was compared with cleaving $\{10 \overline{1} 0\}$ prismatic planes in a WC single crystal. Fracture energies of $7.04 \pm 0.36 \mathrm{Jm}^{-2}$ and $3.57 \pm 0.28 \mathrm{Jm}^{-2}$ were measured for $\{10 \overline{1} 0\}$ plane and $\Sigma 2$ twist boundaries, respectively.

\section{INTRODUCTION}

Cemented carbide (WC-Co) cutting tools are essential for modern manufacturing, as they are used in drilling, mining, and cutting tool inserts. ${ }^{1}$ These WC-Co composites consist of tungsten carbide and cobalt that act as hard particle and binder, respectively. ${ }^{2}$ WC-Co has a higher toughness relative to other hardmaterials, such as polycrystalline diamond with $\mathrm{K}_{\mathrm{IC}}$ in the range of $8-26 \mathrm{MPam}^{1 / 2}$. $^{3}$ Yet, WC-Co tools are limited in performance and lifetime owing to wear and fracture. Hence, crack propagation and fracture in WC-Co has been extensively studied. ${ }^{4-6}$

In WC-Co, cracks can propagate near the $\mathrm{WC} / \mathrm{Co}$ interface, along WC/WC boundaries and transgranular in the carbide. ${ }^{4}$ Formation of a multiligament zone during $\mathrm{WC} / \mathrm{Co}$ failure is the main source of toughening in WC-Co. ${ }^{7}$ However, typically, a smaller fraction of the crack path is along WC/Co phase boundaries at lower binder fractions. ${ }^{4,6}$ Currently, we lack detailed knowledge of WC/WC boundary properties despite a large fraction of the fracture path being along it. This motivates us to study WC/ WC boundary fracture, to provide an opportunity to enhance understanding of the life span of hardmetal-based machining parts.

(Received January 14, 2021; accepted March 17, 2021;

published online April 28, 2021)

\section{TUNGSTEN CARBIDE CRYSTAL STRUCTURE AND 22 BOUNDARIES}

WC has a simple hexagonal crystal with one carbon and a tungsten atom per primitive unit cell. Its c/a ratio is close to unity as the lattice parameters, $\mathrm{a}$ and $\mathrm{c}$, are $0.2906 \mathrm{~nm}$ and $0.2837 \mathrm{~nm}$, respectively. ${ }^{8}$ Alternating layers of $\mathrm{W}$ and $\mathrm{C}$ planes are present along the $\langle 10 \overline{1} 0\rangle$ and $\langle 0001\rangle$ of a WC crystal. While WC grains adopt either an equilibrium triangular prism shape or a truncated trigonal prism, as shown in Fig. 1a. ${ }^{9}$

The high toughness hardmetal microstructure is formed during processing. The cobalt metal binder melts and wets the carbide particles with a dihedral angle of zero during liquid phase sintering. ${ }^{10,11}$ Anisotropy in the WC/Co interface energy means that the presence of cobalt during sintering promotes the growth of three of the prismatic planes compared to the other three in a WC grain, as corresponding pairs of prismatic planes (e.g., (10 $\overline{1} 0)$ and (1010)) are not equivalent because the WC crystal structure is non-centrosymmetric. ${ }^{12}$

The two types of prismatic planes are illustrated in Fig. 1b. The difference between the prismatic plane types can be inferred from the number of dangling bonds for a given atom at the terminating layer. If each of the terminating $\mathrm{W}$ or $\mathrm{C}$ atoms have 4 dangling bonds, the prismatic plane is of type I. 
(a)

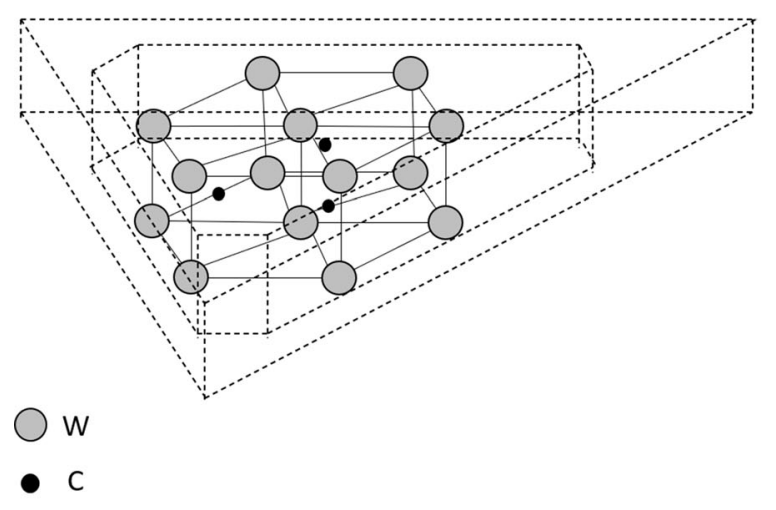

(b)

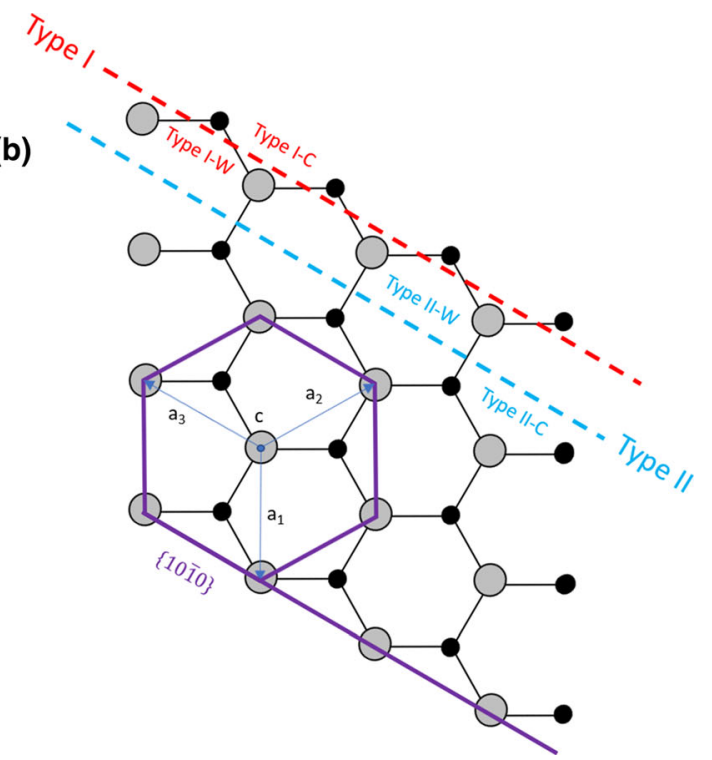

Fig. 1. (a) The hcp unit cell of WC as well as possible growth of the grains into either the equilibrium triangular prism or truncated trigonal prism shapes. (b) Type I and type II prismatic planes as seen from the [0001] direction. Potential ways of cleaving a prismatic plane are also shown in the illustration by dashed lines.

Table I. Surface energies of WC crystallographic planes as obtained from the literature from DFT calculations for carbon-deficient and -rich conditions

\begin{tabular}{|c|c|c|c|c|c|c|c|}
\hline \multirow[b]{3}{*}{ Crystal plane } & \multirow[b]{3}{*}{ Termination } & \multicolumn{6}{|c|}{ Surface energy $\left(\mathrm{Jm}^{-2}\right)$} \\
\hline & & \multicolumn{3}{|c|}{ C-deficient } & \multicolumn{3}{|c|}{ C-rich } \\
\hline & & Ref14 & Ref15 & Ref16 & Ref14 & Ref15 & Ref16 \\
\hline$(0001)$ & $\mathrm{W}$ & 3.45 & 2.9941 & - & 3.77 & 3.5933 & - \\
\hline$(0001)$ & $\mathrm{C}$ & 6.07 & 6.3984 & - & 5.75 & 5.7977 & - \\
\hline 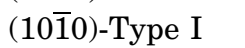 & $\mathrm{W}$ & 5.07 & 4.4712 & 5.0896 & 5.44 & 5.1841 & 5.3891 \\
\hline (10) 10$)$-Type I & $\mathrm{C}$ & 9.02 & 9.6008 & 8.7597 & 8.64 & 8.7277 & 8.4698 \\
\hline (1010)-Type II & $\mathrm{W}$ & 3.77 & 3.4971 & 3.7391 & 3.96 & 3.8528 & 3.8800 \\
\hline 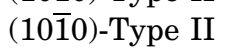 & $\mathrm{C}$ & 3.56 & 3.7503 & 3.5100 & 3.37 & 3.3946 & 3.3690 \\
\hline
\end{tabular}

On the other hand, the prismatic plane is type II if there are 2 dangling bonds per terminating surface atom. The interplanar spacing is also different between the two types of prismatic planes. Interplanar spacing between type I W and C planes is $0.084 \mathrm{~nm}$ in comparison to $0.168 \mathrm{~nm}$ for type II W and C planes. ${ }^{13}$ Density functional theory (DFT) studies have been conducted to determine $\{10 \overline{1} 0\}$ surface energies. A summary of such DFT data is given in Table I.

There are two ways to cleave prismatic planes as shown in Fig. 1b. The crystal can be cleaved between either a type I W and C terminated planes, or a type II $\mathrm{W}$ and $\mathrm{C}$ terminated planes. The cleavage energies (defined as twice the surface energy) in these two scenarios have been determined to be $13.85-14.09 \mathrm{Jm}^{-2}$ and $7.25-7.33 \mathrm{Jm}^{-2}$, respectively, in the literature. ${ }^{14-16}$ Four W-C bonds are broken per unit surface in the former compared to two in the latter. This explains the difference in energy by a factor of 2 . The anisotropic plane energies explain the faceted morphology of WC grains due to preferential growth of $\{0001\}$ and type II $\{10 \overline{1} 0\}$ low-energy planes. Hence, WC-Co is likely to contain straight WC/WC boundaries and, for a (near) random crystallographic texture, some of these will be perpendicular to the surface. This makes WC/WC boundaries suitable for fracture analysis using a DCB test.

WC's c/a ratio being close to unity results in several coincidence site lattice (CSL) boundaries. ${ }^{8}$ $\Sigma 2$ boundaries with a misorientation of $90 \% /[10 \overline{10} 0]$ are the most frequently encountered CSL WC/WC boundaries in WC-Co. ${ }^{17} \Sigma 2$ twist in particular which 
has $\{10 \overline{1} 0\} /\{10 \overline{1} 0\}$ boundary habit planes are most often found owing to lower energy relative to the tilt counterpart. ${ }^{18-20}$ It is important to study the most frequent boundaries to understand the macroscopic performance of the WC-Co tools. Our study can inform grain boundary engineering (GBE) approaches to control microstructure, and ultimately lead to an increase in WC-Co tool performance.

\section{MICROMECHANICAL FRACTURE TESTING}

Study of brittle fracture has advanced significantly owing to Griffith's work. ${ }^{21}$ Here, we return to his premise that the energy required for fracture is directly related to energy needed to create two new surfaces. To provide a mechanistic understanding of the toughness of ceramics at a microscopic scale, micromechanical testing can be applied where individual microstructural features are tested to reveal physical properties, such as fracture energy.

Four microscale fracture testing techniques are used for determining fracture properties: pillar splitting, ${ }^{22}$ single cantilever bending, ${ }^{23,24}$ clamped beam bending, ${ }^{25,26}$ and DCB compression. ${ }^{27}$ These are prone to limitations in sample fabrication and testing, with issues concerning ion implantation at the crack tip ${ }^{28}$ and unstable crack growth, respectively. These issues can lead to erroneous fracture energy measurements.

To address these challenges, a new displacementcontrolled DCB geometry loaded by a wedge tip was introduced in the work of Sernicola et al. ${ }^{29}$ The wedge-loaded DCB geometry allows for a stable crack growth. A stable crack growth in turn facilitates the measurement of fracture energy values further away from notch tip which are more accurate. This technique was designed to use the in situ SEM observation of the crack length as well as physical measurement of each beam flexure to measure the critical energy release rate while the DCB cracks. This was inspired by the macroscopic wedge-loaded DCB test fixture of Obreimoff's in mica. ${ }^{30}$

Sernicola et al. fabricated a DCB vertically using a focused ion beam (FIB), with a 'slot' to accept a wedge indenter. The DCB is deformed using direct displacement control, using a piezo-driven diamond wedge indenter, inside a scanning electron microscope (SEM). This geometry is stable, as the continued movement of the wedge downwards opens up the crack, but more displacement is required for the crack to progress further. Therefore, the strain energy release rate of the crack grown within the DCB can be measured. ${ }^{31}$ Load cell information is not used, and the energy is calculated from the statics of the loaded double cantilever system.

In the present work, we apply the method of Sernicola et al. ${ }^{29}$ to determine the fracture properties of WC-Co, which include the fracture energy of WC/WC $\Sigma 2$ twist boundaries and the [1010] prismatic plane. The grain boundaries were found using electron backscatter diffraction (EBSD) and analysis with MTEX. ${ }^{32}$

$\Sigma 2$ twist boundary strength has been determined in the literature using single cantilever bending tests. ${ }^{33}$ However, the fracture energy of carbide boundaries has never been experimentally reported. Thus, we have used a wedge loaded DCB geometry to measure the fracture energy of $\Sigma 2$ twist boundaries. We have also measured the surface energy of type II $\{10 \overline{1} 0\}$ prismatic planes and compared it to values obtained from the literature.

\section{METHODS}

\section{Materials}

The WC single crystal used in the study was provided by the National Physical Laboratory (NPL). It was grown in a furnace at Sandvik Hard Materials (Coventry, UK).

The multigrain sample used for $\Sigma 2$ boundary analysis was prepared using conventional powder metallurgy routes. Pure WC and Co powders were mixed by milling in ethanol- $10 \% \mathrm{H}_{2} \mathrm{O}$, using extracoarse WC from Wolfram Bergbau FSSS (Fisher Sub Sive grainsize) of $15 \mu \mathrm{m}$, cobalt from Freeport and Polyethylengylcol as a pressing agent to make a WC-10wt\%Co sample. To achieve as large WC grains as possible, the samples were only milled for $4 \mathrm{~h}$ in a WC-lined $0.25 \mathrm{~L}$ rotating mill. Thereafter, the powder was pan dried at $40^{\circ} \mathrm{C}$ in gaseous $\mathrm{N}_{2}$ and finally uniaxially pressed into rectilinear (SNUN) geometry. Followed by de-binding in gaseous $\mathrm{H}_{2}$ to $450^{\circ} \mathrm{C}$ and sintered at $1500^{\circ} \mathrm{C}$ in controlled vacuum. The cemented carbide sample was cut into a $15 \times 5 \times 5 \mathrm{~mm}$ piece using an IsoMet 1000 precision cutter equipped with a diamond cutoff wheel.

The single-crystal and the cemented carbide samples were mounted on a disc grinder and a resin mount, respectively, for grinding, and then they were polished with polycrystalline diamond suspensions with particle sizes of $3 \mu \mathrm{m}, 1 \mu \mathrm{m}$, and $0.25 \mu \mathrm{m}$. Finally, the cemented carbide sample was broad argon ion beam-polished in a PECS II system at $6 \mathrm{kV}$ for $6 \mathrm{~h}$ with the ion beam glancing over the sample surface at an incidence angle of $0^{\circ}$.

\section{Micromechanical Testing Theory}

A DCB as illustrated in Fig. 2 is essentially two cantilever arms clamped at one of the ends, the crack tip. As a wedge is driven into the central trough of a DCB, the cantilever arms are point loaded at the arm-wedge contact. Elastic strain energy stored in the cantilever arms is then released and used for crack initiation and propagation.

The elastic strain energy, $U_{M}\left(\mathrm{Jm}^{-1}\right)$, stored in each of the arms is given by the Euler-Bernoulli beam theory (EBT) in Eq. $1 .^{34}$ The elastic strain 


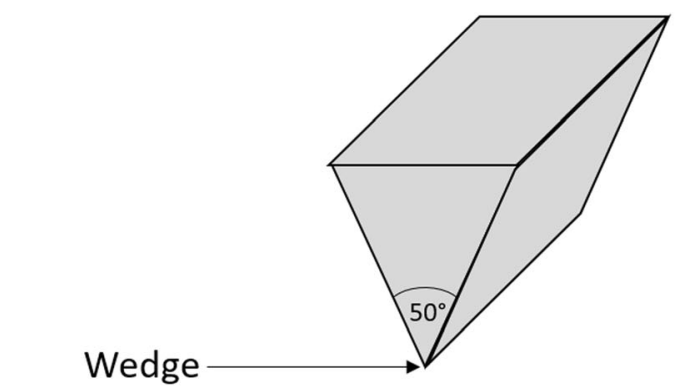

$$
G=-\frac{d U}{d a}=\frac{3 E d^{3} \delta^{2}}{8 a^{4}}\left(1+(1+v)\left(\frac{d}{a}\right)^{2}\right)
$$

where $v$ is the Poisson's ratio. Equation 3 reduces to Eq. 2 as the crack evolves and a $>>$ d. Rotation at the crack tip (clamped end) is corrected for by the solution developed by Williams. ${ }^{36}$ This involves replacing $a$ in Eqs. 2 or 3 with $a+\chi h$. Factors $\chi$ and $\Gamma$ in turn are given in Eqs. 4 and 5, respectively.

$$
\begin{gathered}
\chi=\sqrt{\frac{2(1+v)}{11}}\left[3-2\left(\frac{\Gamma}{1+\Gamma}\right)^{2}\right]^{\frac{1}{2}} \\
\Gamma=2.36(1+v)
\end{gathered}
$$

The value of $\chi$ was approximated to be 0.67 by Williams, with the assumption of the arm being isotropic, as is necessary for applying any beam theory. $\chi$ was also shown to be insensitive to $v$. The validity of the correction was verified in the work of Aldegaither et al. ${ }^{37}$

\section{EBSD Data Collection and Analysis}

EBSD data were acquired using a Bruker eFlashHD EBSD detector in a FEI Quanta 650 FEGESEM. The mapping area for acquisition was marked with four fiducial crosses to form a square grid of $400 \times 400 \mu \mathrm{m}$ area. Data were recorded with a step size of $0.4 \mu \mathrm{m}$. Once acquired, it was loaded into MTEX 5.1.1 in MATLAB. A custom script in MATLAB was then used for data analysis to identify $\Sigma 2$ twist boundaries for mechanical testing,

Fig. 2. Schematic of a DCB geometry loaded via a wedge. $l, d, t$, and $a$ are DCB length, cantilever arm width, thickness, and crack length, respectively.

energy release rate, $G\left(\mathrm{Jm}^{-2}\right)$, in accordance with the Griffith criterion for this case is as in Eq. 2.

$$
\begin{gathered}
U_{M}=\frac{E d^{3} \delta^{2}}{8 a^{3}} \\
G=-\frac{d U_{M}}{d a}=\frac{3 E d^{3} \delta^{2}}{8 a^{4}}
\end{gathered}
$$

where $E, d, \delta$, and $a$ are the elastic modulus, cantilever arm width, arm lateral displacement, and crack length, respectively. $G$ will give values of surface energy provided that the energy expended in bending the arms is the same as the energy stored in them. During initial crack growth, the EBT assumption of $a<<d$ is not valid. Hence, the Timoshenko beam theory (TBT) model for analyzing the behavior of short thick beams must be used. ${ }^{35}$ TBT accounts for the effects of transverse shear deformation during loading. $G$ for each beam during early crack propagation is given as: i.e., those with grain boundary planes perpendicular to the cut sample surface.

$\Sigma 2$ boundaries were identified in MTEX based on the following criteria: grains sharing a $\Sigma 2$ boundary will have $\{10 \overline{1} 0\}||\{10 \overline{1} 0\}$ and $\{0001\}||\{11 \overline{2} 0\}$ relationships. In polycrystalline WC, the $\Sigma 2$ twist and tilt boundary types have a different habit plane. The twist has two $\{10 \overline{1} 0\}$ planes terminating the crystals at the interface. The tilt has $\{0001\}$ and a $\{11 \overline{2} 0\}$ terminating each crystal. In this work, only the $\Sigma 2$ twist boundary is of interest.

To find the boundaries of interest, the two habit planes were transformed from the crystal frame of reference into the sample frame, using the transformation in equations 6 and 7.

$$
\begin{aligned}
& g_{a} \times\{10 \overline{1} 0\}=6 \times v_{a} \\
& g_{b} \times\{10 \overline{1} 0\}=6 \times v_{b}
\end{aligned}
$$

where $\boldsymbol{g}$ is the rotation matrix for each grain, while $a$ and $b$ are adjacent grains sharing a boundary. Six vectors are produced for each grain as there are six prismatic planes. The parallel planes are determined using a dot product test of the (unit) plane normal vector. For the planes pairing that is 
parallel, a second dot product test is used to compare this vector with the surface normal, i.e., if the shared plane is perpendicular to the surface normal. This identifies a subset of boundaries within the region of interest in which DCBs can be cut.

\section{DCB Manufacture}

The micromechanical test specimens were machined from specific sites using a FEI Helios NanoLab 600 DualBeam SEM. A custom script written in the Nano-Builder software was used for automated fabrication of DCBs following the method outlined by Sernicola et al. ${ }^{29}$

\section{Micromechanical Testing Procedure}

Single-crystal DCB fracture tests were performed on a [0001] oriented grain, cleaving $\{10 \overline{1} 0\}$ prismatic planes apart. DCB tests were also conducted on the WC-10wt\%Co sample to measure the fracture energy of the $\Sigma 2$ twist boundary.

Micromechanical testing was conducted in situ within a FEI Quanta 650 FEG-ESEM microscope. This afforded continuous high spatial resolution imaging of the test process. Thus, alignment of the DCB with the indenter tip and tracking crack propagation was possible. Images were captured using an Everhart-Thornley detector in secondary electron mode at $5 \mathrm{kV}$ and a working distance of $\sim 10$ $\mathrm{mm}$.

An Alemnis nanoindenter was used for DCB testing. DCBs were loaded with a $50^{\circ}$ cone angle and 10- $\mu \mathrm{m}$-long, diamond wedge tip (Synton) in direct displacement control. Images were acquired at $\sim 500-\mathrm{ms}$ intervals during testing. Lateral arm displacement, arm width, and crack length were extracted from these images with the aid of custom MATLAB scripts. Linearly-fitted lateral displacement of the beams and linearly-fitted crack length data were utilized for fracture energy determination. This was done with the intention of reducing noise/scatter in the measurements. Further details regarding the test procedure can be found in the work by Sernicola et al. ${ }^{29}$

\section{Results}

Figure 3 a shows one of the regions selected for EBSD analysis marked with FIB-milled fiducial crosses. The locations of the fiducial crosses had FIB damage and were not indexed during EBSD acquisition, as seen in Fig. 3b. A large pore located at the top region of interest (ROI) is also seen in the image. The microstructure of the sample shows WC grains and Co binder ligaments as relatively bright and dark areas, respectively, in Fig. 3a. Figure 3b shows a schematic of grain boundaries with $\Sigma 2$ boundaries indicated in red. The twist and tilt variants were not distinguished at this point. Employing the method detailed in the section, EBSD data analysis, $\Sigma 2$ twist boundaries were identified.

EBSD analysis of a $\Sigma 2$ twist boundary site from the ROI is shown in Fig. 4. Both the image quality map and forescattered electron micrograph from Fig. $4 \mathrm{~b}$ and $\mathrm{c}$ around one such site indicate the presence of a boundary at the expected location. The habit planes at this boundary being prismatic $(10 \overline{1} 0)$ and perpendicular to the surface are conveyed via EBSD IPF map overlaid with equilibrium WC crystal shapes in Fig. 4c.

First, the WC single crystal was split, and micrographs from a representative in situ test are shown in Fig. 5a. The single crystal was oriented with [0001] plane normal along the displacement direction of the wedge indenter and that $\{10 \overline{1} 0\}$ plane was cleaved. Then, DCB tests were performed at $\Sigma 2$ twist boundaries sites. Fig. 5b shows a successful DCB test at a $\Sigma 2$ twist boundary.

Fractures energies presented in Fig. 6a were evaluated with cantilever arm displacement, arm width, and crack length as measured from test images and the elastic modulus determined using elastic constants taken from Landolt-Börnstein ${ }^{38}$ in accordance with Hearmon's work. ${ }^{39}$ In the case of the [0001]-oriented single crystal, an elastic modulus of $825.6 \mathrm{GPa}$ was used. For the $\Sigma 2$ twist

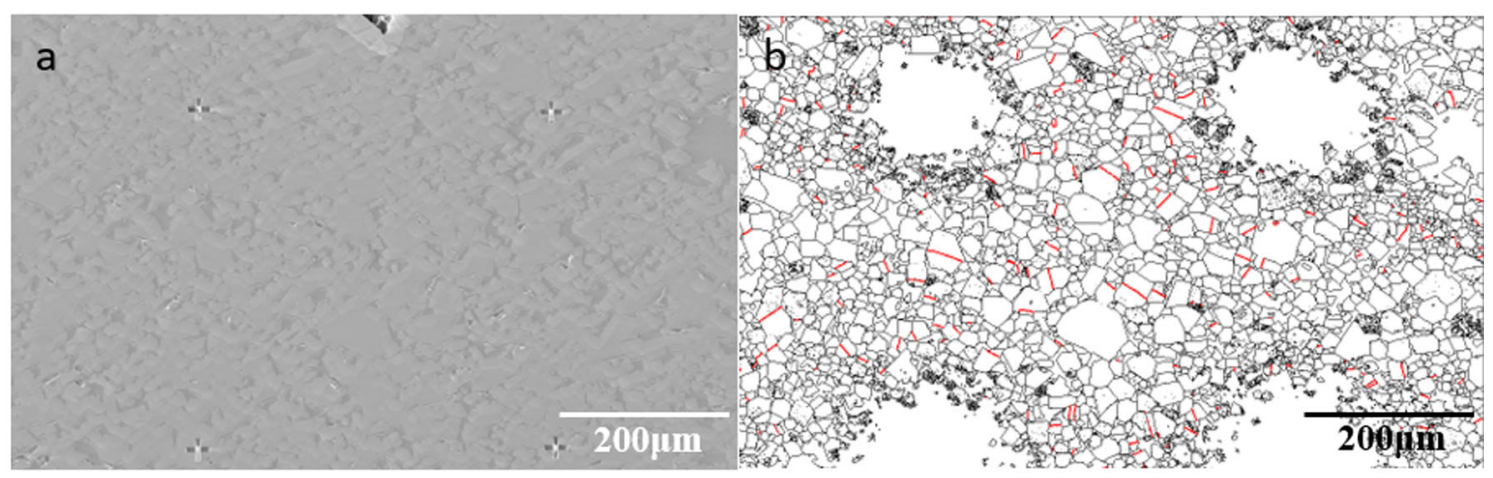

Fig. 3. (a) SEM image of a region selected for EBSD analysis from a WC-10wt\%Co sample in SE mode. The image was captured while the sample had been tilted by $70^{\circ}$. (b) Schematic of grain boundaries plotted for the same region. All possible $\Sigma 2$ boundaries have been highlighted in red. 


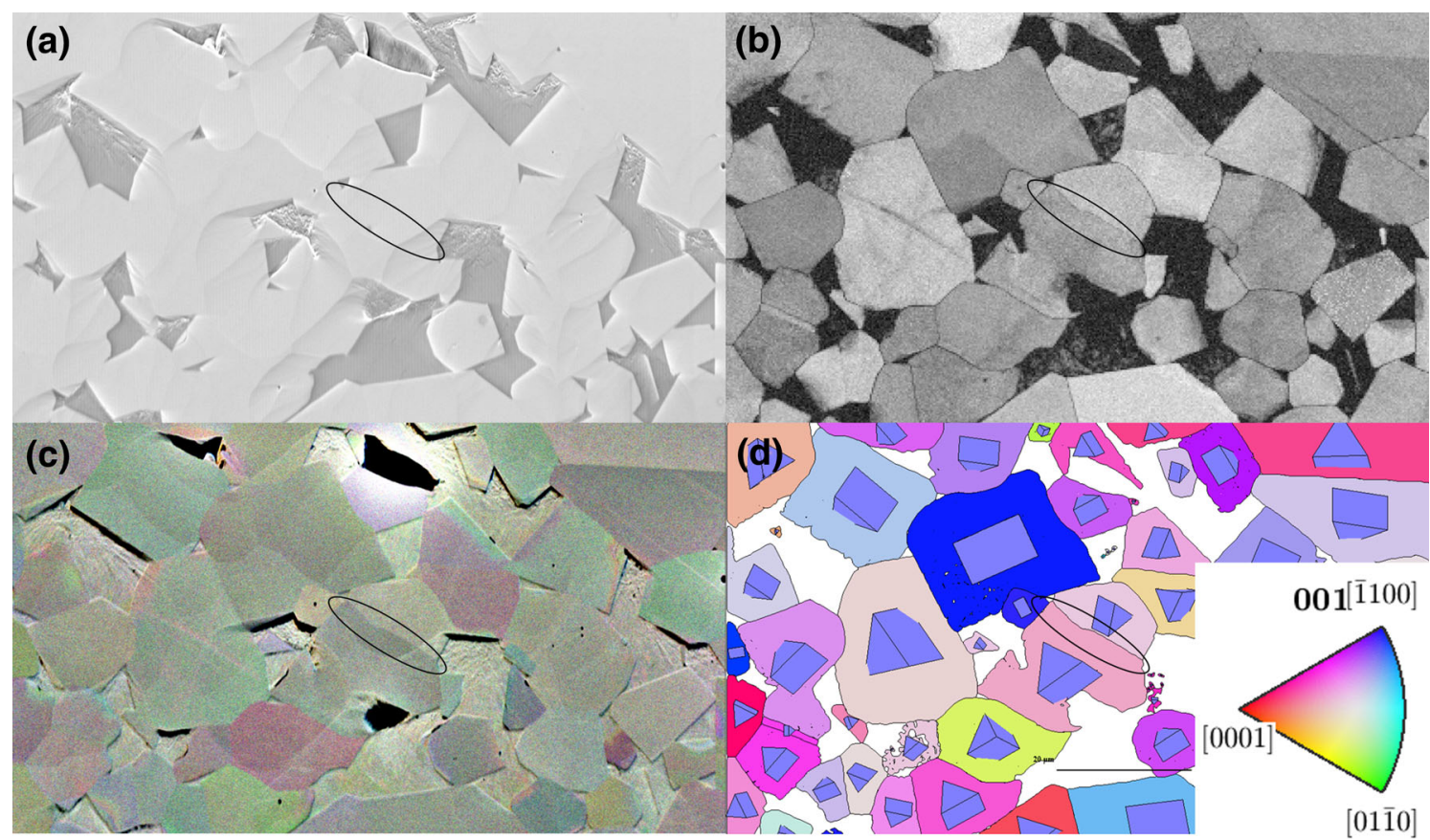

Fig. 4. (a) SEM image in SE mode, (b) image quality map, (c) forescattered electron micrograph, and (d) EBSD IPF map with WC crystal shapes overlaid for the selected $\Sigma 2$ twist boundary site. WC crystal shapes are depicted as equilibrium triangular prism shapes.

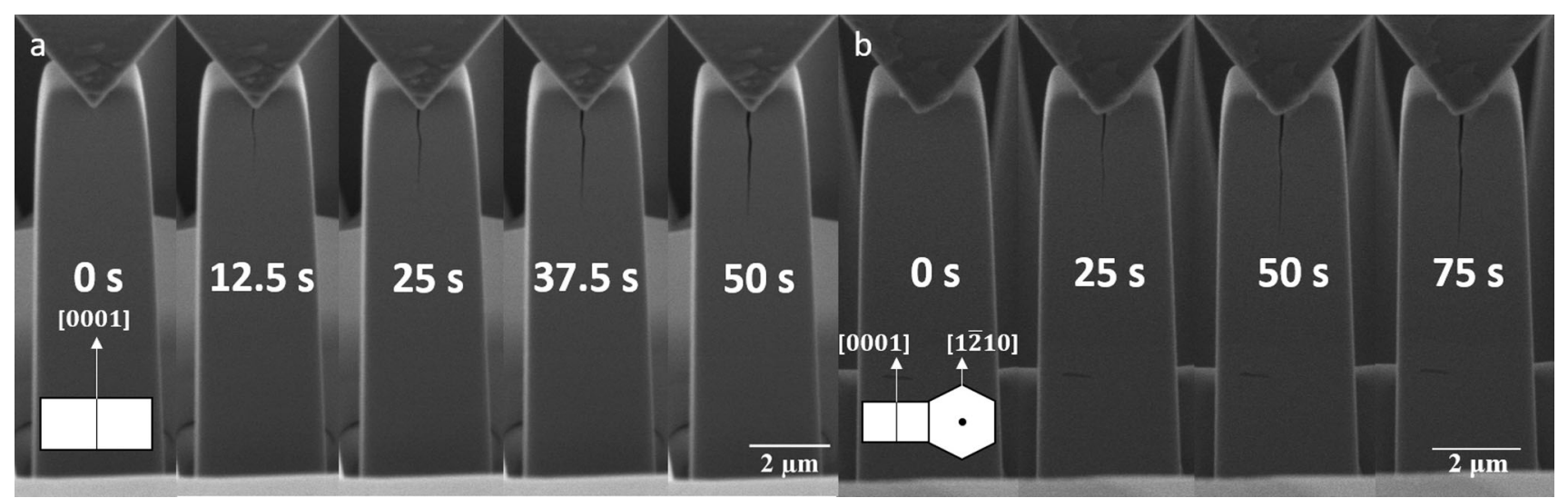

Fig. 5. SEM images of the frames from a successful (a) single-crystal DCB test (SC1) at $0 \mathrm{~s}, 12.5 \mathrm{~s}, 25 \mathrm{~s}, 37.5 \mathrm{~s}$, and $50 \mathrm{~s}$, and (b) a $\Sigma 2$ boundary DCB test at $0 \mathrm{~s}, 25 \mathrm{~s}, 50 \mathrm{~s}$, and $75 \mathrm{~s}$ in SE mode.

boundaries, elastic moduli were calculated depending on grain orientation. Orientation and elastic moduli of $\Sigma 2$ boundary grains is provided in Table II.

\section{DISCUSSION}

DCB tests have been performed on a WC single crystal cleaving $\{10 \overline{1} 0\}$ planes and compared with tests that measure the $\Sigma 2$ twist boundary. There, the fracture energy of the $\{10 \overline{1} 0\}$ plane was measured as $7.04 \pm 0.36 \mathrm{Jm}^{-2}$, agreeing with the DFT data $\left(\sim 7.33 \mathrm{Jm}^{-2}\right)$ if it is assumed that the lowenergy plane is fractured.
Fracture energy determined from DCB wedge testing of $\Sigma 2$ twist boundaries was $3.57 \pm 0.28 \mathrm{Jm}^{-2}$. This lower fracture energy is lower than for the $\{10 \overline{1} 0\}$ planes, suggesting that the twist boundaries are more susceptible for crack propagation than the carbide grains, as expected. A comparison of the fracture energies from each of the DCB test are given in Fig. $6 \mathrm{~b}$.

Fracture energies of boundaries $\Sigma 2 \mathrm{~B} 1$ and $\Sigma 2 \mathrm{~B} 3$ increase near the end of their respective crack paths. The increase in energy is a consequence of that the cracks are deviating from a straight path and onto the sides of the DCBs. Bending of a crack results in the thickness of the cantilever arms (which is assumed to be constant) not being well 
defined, and the equation for calculating fracture energy is thus no longer valid. In the case of the DCBs at the grain boundaries, it must be noted that
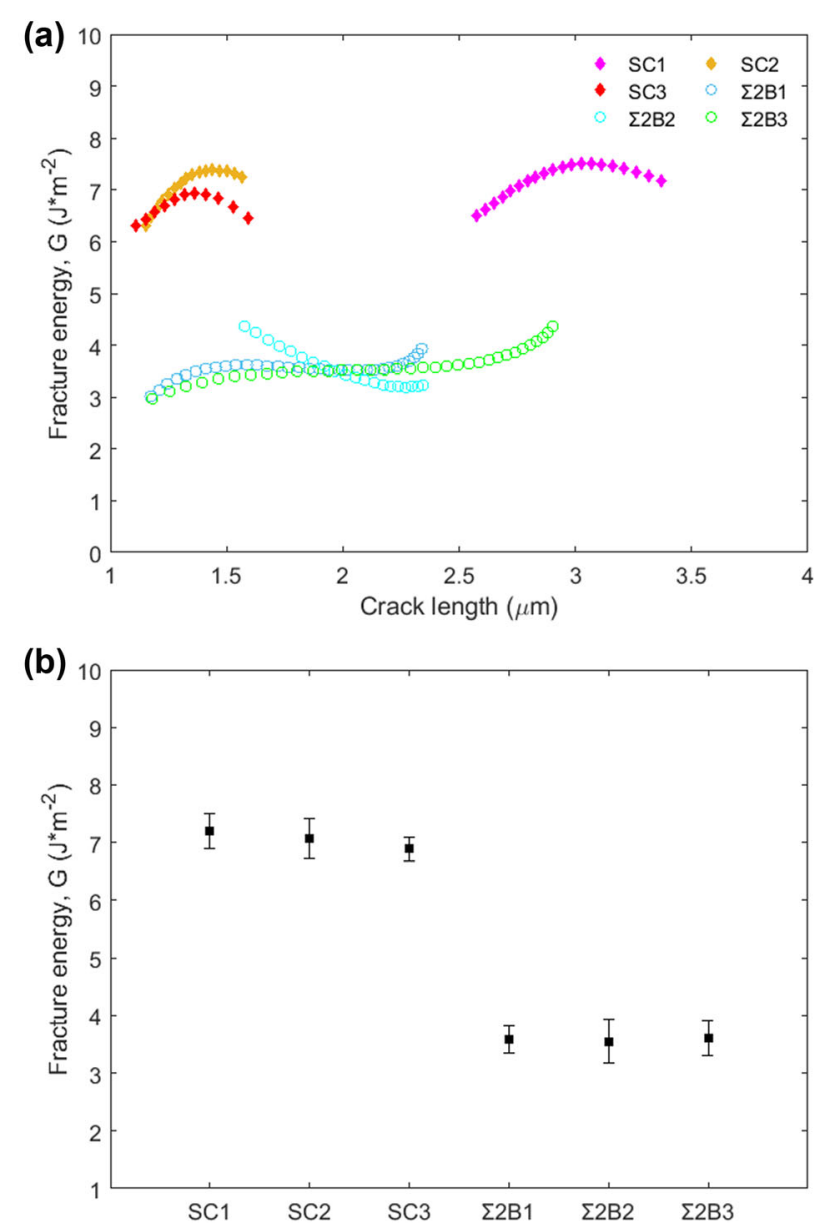

Fig 6. (a) Fracture energy plotted as a function of crack length for three successful DCBs on the WC single crystal (SC1, SC2, and SC3) and three $\Sigma 2$ twist boundaries ( $\Sigma 2 \mathrm{~B} 1, \Sigma 2 \mathrm{~B} 2$, and $\Sigma 2 \mathrm{~B} 3$ ). (b) Average fracture energies calculated from the same DCB tests with the error bars depicting scatter of data. milling DCBs with the boundary sitting at the exact middle of a DCB geometry is challenging. Thus, a DCB notch is unlikely to be at the exact location of a boundary. Hence, it is likely that the crack initiates away from the boundary locale. However, it will eventually jump onto the low energy fracture path-, i.e., the boundary.

In contrast, cracks do not have a clear preferred path for propagation in a WC single crystal. This is because surface energies of some of the WC planes are similar. For example, type II $\{10 \overline{1} 0\}$ and $\{0001\}$ plane energies are similar. Thus, a crack will eventually deviate from the intended straight path (along type II $\{10 \overline{1} 0\}$ ) in a WC single crystal. Consequently, straight cracks in WC single-crystal DCBs are shorter compared to the boundary DCBs. There is also variability in the fracture energy for any given DCB test, as illustrated in Fig. 6a. This is potentially the result of the crack not propagating exactly straight.

\section{CONCLUSION}

DCB wedging tests have been performed on a WC single-crystal sample cleaving $\{10 \overline{1} 0\}$ planes. Measured fracture energy values $\left(7.04 \pm 0.36 \mathrm{Jm}^{-2}\right)$ are similar to the cleavage energy values in the literature, determined from DFT calculations. We have devised a method to identify CSL boundaries within a microstructure, perpendicular to the surface from EBSD data analysis. $\Sigma 2$ twist boundaries were identified via this process on a WC- $10 \mathrm{wt} \%$ Co sample. Fracture tests were conducted on such boundary features, producing precise measurements of $\Sigma 2$ twist boundary energy $\left(3.57 \pm 0.28 \mathrm{Jm}^{-2}\right)$. This information is useful when controlling WC-Co microstructure via GBE.

\section{ACKNOWLEDGEMENTS}

The authors would like to thank Seco Tools AB and MAPP (EPSRC EP/ N509486/1) for funding this project. We also would like to thank Gary Sweetman

Table II. Grain orientations of WC grains at $\Sigma 2$ boundaries of interest and their corresponding elastic moduli

\begin{tabular}{|c|c|c|c|c|c|}
\hline \multirow[b]{2}{*}{ Boundary } & \multicolumn{3}{|c|}{ Euler angles (degrees) } & \multirow{2}{*}{$\frac{\text { Directions }}{\text { [UVTW] }}$} & \multirow[b]{2}{*}{ Elastic modulus (GPa) } \\
\hline & $\phi_{1}$ & $\Phi$ & $\phi_{2}$ & & \\
\hline \multirow[t]{2}{*}{$\Sigma 2 \mathrm{~B} 1$} & 159.2 & 23.0 & 195.0 & {$[1 \overline{4} 310]$} & 821.55 \\
\hline & 55.9 & 83.8 & 278.5 & {$[\overline{12} 2101]$} & 600.21 \\
\hline \multirow[t]{2}{*}{$\Sigma 2 \mathrm{~B} 2$} & 52.4 & 41.0 & 308.3 & {$[\overline{8} 539]$} & 776.20 \\
\hline & 243.0 & 51.9 & 113.5 & 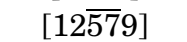 & 724.07 \\
\hline \multirow{2}{*}{$\Sigma 2 \mathrm{~B} 3$} & 2.7 & 79.1 & 356.1 & {$[\overline{6} 11 \overline{5} 2]$} & 608.53 \\
\hline & 147.3 & 8.4 & 217.6 & {$[0 \overline{1} 18]$} & 826.00 \\
\hline
\end{tabular}

Grain orientations are given as Euler angles in the Bunge convention as well as Miller indices of the direction out of sample. Miller indices have been rounded off to integer values 
from Sandvik Hard Materials (Coventry, UK) and Helen Jones from NPL for the supply of WC single crystals used in this study. We would also like to thank Ida Borgh from Sandvik Mining (Stockholm, Sweden) for discussions regarding polishing of WCCo. Finally, we gratefully acknowledge Prof. Luc Vandeperre's (Imperial College London) help with calculating WC elastic moduli as well as fruitful discussions.

\section{CONFLICT OF INTEREST}

The authors declare that they have no conflict of interest.

\section{OPEN ACCESS}

This article is licensed under a Creative Commons Attribution 4.0 International License, which permits use, sharing, adaptation, distribution and reproduction in any medium or format, as long as you give appropriate credit to the original author(s) and the source, provide a link to the Creative Commons licence, and indicate if changes were made. The images or other third party material in this article are included in the article's Creative Commons licence, unless indicated otherwise in a credit line to the material. If material is not included in the article's Creative Commons licence and your intended use is not permitted by statutory regulation or exceeds the permitted use, you will need to obtain permission directly from the copyright holder. To view a copy of this licence, visit $h$ ttp://creativecommons.org/licenses/by/4.0/.

\section{REFERENCES}

1. R.E. Krebs, The History and use of our Earth's Chemical Elements: A Reference Guide, 2nd edn. (Greenwood, Westport, 2006), p 154.

2. M. Srinivasan, and W. Rafaniello, Carbide, Nitride and Boride Materials Synthesis and Processing, 1st edn. (Chapman \& Hall, London, 1997), pp 10-12.

3. K. Ravichandran, Acta Metall. Mater. 42, 143. (1994).

4. L.S. Sigl, and H.F. Fischmeister, Acta Metall. 36, 887. (1988).

5. L. Llanes, Y. Torres, and M. Anglada, Acta Mater. 50, 2381. (2002).

6. K.P. Mingard, H.G. Jones, M.G. Gee, B. Roebuck, and J.W. Nunn, Int. J. Refract. Met. Hard Mater. 36, 136. (2013).

7. A. G. Evans, A. H. Heuer, D. L. Porter and D. M. R. Taplin, Proceedings of the 4th International Conference on Fracture, (New York: Pergamon, 1977), pp. 529-556.

8. S. Hagege, J. Vicens, G. Nouet, and P. Delavignette, Phys. Status Solidi A 61, 675. (1980).

9. H. Exner, Int. Met. Rev. 24, 149. (1979).
10. J. Gurland, and J.T. Norton, JOM 4, 1051. (1952).

11. L. Ramqvist, Int. J. Powder Metall. 1, 2. (1965).

12. F. Vahldiek, Anisotropy in Single-Crystal Refractory Compounds, 1st edn. (Springer, New York, 1968), pp 55-66.

13. S. Lay, P. Donnadieu, and M. Loubradou, Micron 41, 472. (2010).

14. M.V. Petisme, S.A. Johansson, and G. Wahnström, Modell. Simul. Mater. Sci. Eng. 23, 045001. (2015).

15. Y. Zhong, H. Zhu, L.L. Shaw, and R. Ramprasad, Acta Mater. 59, 3748. (2011).

16. B. Yoon, B. Lee, and S.L. Kang, Acta Mater. 53, 4677. (2005).

17. S. Hagége, G. Nouet, and P. Delavignette, Phys. Status Solidi A 62, 97. (1980).

18. M. Christensen, and G. Wahnström, Acta Mater. 52, 2199. (2004).

19. K. Mannesson, M. Elfwing, A. Kusoffsky, S. Norgren, and J. Åren, Int. J. Refract. Met. Hard Mater. 26, 449. (2008).

20. X. Yuan, G.S. Rohrer, X. Song, H. Chien, J. Li, and C. Wei, Int. J. Refract. Met. Hard Mater. 47, 38. (2014).

21. A.A. Griffith, Philos. Trans. R. Soc. A 221, 163. (1921).

22. M. Sebastiani, K. Johanns, E.G. Herbert, F. Carassiti, and G.M. Pharr, Philos. Mag. 95, 1928. (2015).

23. D. Di Maio, and S. Roberts, J. Mater. Res. 20, 299. (2005).

24. T. Halford, K. Takashima, Y. Higo, and P. Bowen, Fatigue Fract. Eng. Mater. Struct. 28, 695. (2005).

25. V. Srikar, and S.M. Spearing, Exp. Mech. 43, 238. (2003).

26. N. Jaya, B.V. Jayaram, and S.K. Biswas, Philos. Mag. 92, 3326. (2012).

27. S. Liu, J. Wheeler, P. Howie, X. Zeng, J. Michler, and W. Clegg, Appl. Phys. Lett. 102, 171907. (2013).

28. J.P. Best, J. Zechner, I. Shorubalko, J.V. Oboňa, J. Wehrs, M. Morstein, and J. Michler, Scr. Mater. 112, 71. (2016).

29. G. Sernicola, T. Giovannini, P. Patel, J.R. Kermode, D.S. Balint, T.B. Britton, and F. Giuliani, Nat. Commun. 8, 1. (2017).

30. J. Obreimoff, Proc. R. Soc. Lond. Ser. A 127, 290. (1930).

31. B. Lawn, and T. Wilshaw, Fracture of Brittle Solids, 2nd edn. (Cambridge University Press, Cambridge, 1993), p 37.

32. R. Heilscher., MTEX Toolbox, (2021), https://mtex-toolbox.g ithub.io/. Accessed 13 Dec 2020.

33. M.R. Elizalde, I. Ocaña, J. Alkorta, and J.M. Sánchez-Moreno, Int. J. Refract. Met. Hard Mater. 72, 39. (2018).

34. C. Wang, J.N. Reddy, and K. Lee, Shear Deformable Beams and Plates: Relationships with Classical Solutions, 1st edn. (Elsevier, Amsterdam, 2000), p 11.

35. E. Esmailzadeh, D. Younesian, and H. Askari, Analytical Methods in Nonlinear Oscillations: Approaches and Applications, 1st edn. (Springer, Dordrecht, 2018), p 272.

36. J.G. Williams, Compos. Sci. Technol. 35, 367. (1989).

37. N. Aldegaither, G. Sernicola, A. Mesgarnejad, A. Karma, D. Balint, J. Wang, E. Saiz, S.J. Shefelbine, A.E. Porter, and F. Giuliani, Acta Biomater. 121, 475. (2021).

38. H. Landolt, A. Hellwege, M. Choy, K. Hellwege, and R. Boernstein, Elastische, Piezoelektrische, Pyroelektrische, Piezooptische, Elektrooptische Konstanten Und Nichtlineare Dielektrische Suszeptibilitaeten (Springer, Berlin, 1979).

39. R. Hearmon, Acta Crystallogr. 10, 121. (1957).

Publisher's Note Springer Nature remains neutral with regard to jurisdictional claims in published maps and institutional affiliations. 